\title{
ANALISIS INVENTORI REAKTOR DAYA EKSPERIMENTAL JENIS REAKTOR GAS TEMPERATUR TINGGI
}

\author{
Sri Kuntjoro, Pande Made Udiyani \\ ${ }^{1}$ Pusat Teknologi dan Keselamatan Reaktor Nuklir-BATAN \\ Kawasan Puspiptek, Serpong, Tangerang Selatan, 15314 \\ e-mail: srikuncoro@batan.go.id
}

(Naskah diterima : 29-12-2015, Naskah direvisi: 18-01-2016, Naskah disetujui: 26-01-2016)

\begin{abstract}
ABSTRAK
ANALISIS INVENTORI REAKTOR DAYA EKSPERIMENTAL JENIS REAKTOR GAS TEMPERATUR TINGGI. Berkaitan dengan rencana Badan Tenaga Nuklir Nasional (BATAN) untuk mengoperasikan reaktor eksperimental jenis Reaktor Gas Temperatur Tinggi (RGTT), maka diperlukan analisis keselamatan terhadap reaktor terutama yang berkaitan dengan issue lingkungan. Analisis sebaran radionuklida dari reaktor ke lingkungan pada kondisi operasi normal atau abnormal diawali dengan estimasi sumber radionuklida di teras reaktor (inventori teras) berdasarkan pada tipe, daya, dan operasi reaktor. Tujuan penelitian adalah melakukan analisis inventori teras untuk disain Reaktor Daya Eksperimental (RDE) jenis reaktor gas temperature tinggi berdaya $10 \mathrm{MWt}, 20 \mathrm{MWt}$ dan $30 \mathrm{MWt}$. Analisis dilakukan menggunakan program ORIGEN2 berbasis pustaka penampang lintang pada temperatur tinggi. Perhitungan diawali dengan membuat modifikasi beberapa parameter pustaka tampang lintang berdasarkan temperatur rata-rata teras sebesar $5700{ }^{\circ} \mathrm{C}$ dan dilanjutkan dengan melakukan perhitungan inventori reaktor untuk reaktor RDE berdaya $10 \mathrm{MWt}$. Parameter utama reaktor RDE $10 \mathrm{MWt}$ yang digunakan dalam perhitungan sama dengan parameter utama reaktor HTR-10. Setelah inventori reaktor RDE $10 \mathrm{MWt}$ diperoleh, dilakukan perbandingan dengan hasil dari peneliti terdahulu. Berdasarkan kesesuaian hasil yang didapat dilakukan desain untuk reaktor RDE 20MWEt dan $30 \mathrm{MWt}$ untuk memperoleh parameter utama reaktor tersebut berupa jumlah bahan bakar pebble bed di teras reaktor, tinggi dan diameter teras. Berdasarkan pareameter utama teras dilakukan perhitungan inventori teras RDE $20 \mathrm{MWt}$ dan $30 \mathrm{MWt}$ dengan metode yang sama dengan metode perhitungan pada RDE $10 \mathrm{MWt}$. Hasil yang diperoleh adalah inventori terbesar untuk reaktor RDE $10 \mathrm{MWt}, 20 \mathrm{MWt}$ dan $30 \mathrm{MWt}$ secara berurutan untuk kelompok $\mathrm{Kr}$ adalah sekitar $1,00 \mathrm{E}+15 \mathrm{~Bq}, 1,20 \mathrm{E}+16 \mathrm{~Bq}, 1,70 \mathrm{E}+16 \mathrm{~Bq}$ untuk kelompok I sebesar $6,50 \mathrm{E}+16 \mathrm{~Bq}$, $1,20 \mathrm{E}+17 \mathrm{~Bq}, 1,60 \mathrm{E}+17 \mathrm{~Bq}$ dan untuk kelompok Cs sebesar 2,20E+16 Bq, 2,40E+16 Bq dan $2,60 \mathrm{E}+16 \mathrm{~Bq}$. Inventori teras selanjutnya akan digunakan untuk menghitung suku sumber dari reaktor yang akan digunakan sebagai dasar untuk perhitungan sebaran radionuklida ke lingkungan.
\end{abstract}

Kata kunci: Inventori, RDE, daya $10 \mathrm{MWt}$, daya $20 \mathrm{MWt}$, daya $30 \mathrm{MWt}$. 


\section{ABSTRACT}

\section{THE ANALYSIS FOR INVENTORY OF EXPERIMENTAL REACTOR HIGH TEMPERATURE}

GAS REACTOR TYPE. Relating to the plan of the National Nuclear Energy Agency (BATAN) to operate an experimental reactor of High Temperature Gas Reactors type (RGTT), it is necessary to reactor safety analysis, especially with regard to environmental issues. Analysis of the distribution of radionuclides from the reactor into the environment in normal or abnormal operating conditions starting with the estimated reactor inventory based on the type, power, and operation of the reactor. The purpose of research is to analyze inventory terrace for Experimental Power Reactor design (RDE) high temperature gas reactor type power $10 \mathrm{MWt}, 20 \mathrm{MWt}$ and $30 \mathrm{MWt}$. Analyses were performed using ORIGEN2 computer code with high temperatures cross-section library. Calculation begins with making modifications to some parameter of cross-section library based on the core average temperature of $570{ }^{\circ} \mathrm{C}$ and continued with calculations of reactor inventory due to RDE $10 \mathrm{MWt}$ reactor power. The main parameters of the reactor $10 \mathrm{MWt} R D E$ used in the calculation of the main parameters of the reactor similar to the HTR-10 reactor. After the reactor inventory $10 \mathrm{MWt} R D E$ obtained, a comparison with the results of previous researchers. Based upon the suitability of the results, it make the design for the reactor RDE 20MWEt and $30 \mathrm{MWt}$ to obtain the main parameters of the reactor in the form of the amount of fuel in the pebble bed reactor core, height and diameter of the terrace. Based on the main parameter or reactor obtained perform of calculation to get reactor inventory for RDE 20 MWT and $30 \mathrm{MWT}$ with the same methods as the method of the RDE $10 \mathrm{MWt}$ calculation. The results obtained are the largest inventory of reactor RDE $10 \mathrm{MWt}, 20 \mathrm{MWt}$ and $30 \mathrm{MWt}$ sequentially are to $\mathrm{Kr}$ group are about $1,00 E+15 \mathrm{~Bq}, 1,20 E+16 \mathrm{~Bq}, 1,70 E+16 \mathrm{~Bq}$, for group I are 6,50E+16 Bq, $1,20 E+17 \mathrm{~Bq}, 1,60 \mathrm{E}+17 \mathrm{~Bq}$ and for groups Cs are 2,20E+16 Bq, 2,40E+16 2,60E+16 Bq. Reactor inventory will then be used to calculate the reactor sourceterm and it will be used as the basis for calculating the distribution of radionuclides into the environment.

Keywords: Inventory, RDE, $10 \mathrm{MWt}$ power, $20 \mathrm{MWt}$ power, $30 \mathrm{MWt}$ power. 


\section{PENDAHULUAN}

Badan Tenaga Nuklir Nasional (BATAN) berencana membangun reaktor daya eksperimental (RDE) untuk dapat melakukan eksperimen terkait dengan temperatur tinggi dan pemenuhan sebagian energi listrik untuk lingkungan kawasan PUSPIPTEK. Sehubungan dengan hal tersebut maka dipilih reaktor yang memiliki daya berkisar antara $10 \mathrm{MWt}$ hingga $30 \mathrm{MWt}$ bertipe reaktor gas temperatur tinggi (High Temperatur Gas Reaktor/HTGR). Reaktor tersebut akan dibangun di sebuah kawasan Puspiptek Serpong yang berada di Desa Setu, Kota Tangerang Selatan. Untuk membangun reaktor tersebut diperlukan berbagai izin dari instansi Kementrian Lingkungan Hidup dan Kehutanan (KLHK) dan Badan Pengawas Tenaga Nuklir (BAPETEN) antara lain izin Lingkungan, Analisis Dampak Lingkungan (ANDAL), Program Evaluasi Tapak (PET), izin Tapak, Izin Konstruksi, izin Komisioning dan program dekomisioning. Untuk memenuhi izin tersebut dibuat dokumen-dokumen, dan di dalam dokumen tersebut terdapat bab yang berisi tentang kajian dispersi radionuklida ke lingkungan disekitar reaktor pada kondisi reaktor beroperasi normal maupun abnormal. Untuk melakukan kajian tersebut diperlukan data utama yaitu sourceterm reaktor. Sourceterm yang diperlukan adalah untuk kondisi reaktor beroperasi normal serta reaktor kondisi abnormal yaitu pada kondisi kecelakaan desain dasar (Design Basic Accident/DBA) serta kecelakaan diluar desain dasar (Beyond Design Basic Accident/DBDA). Sourceterm dapat dihitung bila inventori reaktor dapat ditentukan, oleh karenanya analisis untuk mementukan inventori reaktor pada kondisi teras setimbang (equilibrium core) sangat penting untuk dilakukan.

Penentuan inventori reaktor untuk reaktor HTGR cukup sulit, karena saat ini tidak ada reaktor berjenis HTGR yang beroperasi secara komersiil, sehingga terlampau sedikit data kajian atau pustaka yang merepresentasikan. Berbeda dengan reaktor jenis air ringan (Light Water Reaktor/LWR) penentuan inventori reaktor telah banyak dibahas oleh para peneliti seperti ditunjukkan pada data pustaka ${ }^{[1]}$. Berbagai program komputer juga telah dibuat dan digunakan untuk berbagai tipe reaktor. Pada Pressurized Water Reaktor (PWR) dilakukan perhitungan inventori reaktor menggunakan kombinasi perhitungan sel dan deplesi radionuklida (WIMS dan ORIGEN] menggunakan perhitungan teras reaktor ${ }^{[2]}$, juga kombinasi program deplesi radionuklida (ORIGEN2) dengan program transport produk fissi (ASTAC) ${ }^{[3]}$, serta kombinasi program MCODE dan MOCUP sebagai kopling untuk program MCNP-ORIGEN ${ }^{[4]}$. Selanjutnya, untuk melakukan perhitungan inventori dan sourceterm di reaktor air mendidih (Boiling Water Reaktor/BWR) Yamamoto telah menggunakan program kopling MPVBURN $^{[5]}$ dan program SRAC[6]. Selain itu untuk reaktor jenis air berat (Pressuried Heavy Water Reaktor/PHWR) untuk perhitungan yang sama menggunakan program WIMSD4[7], kombinasi program ORIGENARP dengan program SCALE ${ }^{[8]}$ serta kombinasi program ORIGEN dengan program MCNP[9].

Reaktor Daya Eksperimental yang akan dibangun di kawasan Puspiptek Serpong-Tangerang Selatan merupakan reaktor jenis temperatur tinggi berpendingin gas (reaktor HTGR). Beberapa peneliti telah melakukan penelitian untuk reaktor HTGR, antara lain tentang teras reaktor HTGR merujuk pada pustaka ${ }^{[10,11,12,13,14,15,16]}$, juga pene-litian tentang bahan bakar TRISO oleh peneliti sesuai pustaka ${ }^{[17,18,19]}$. Penelitian lain juga melakukan penelitian tentang keselamatan reaktor HTGR yaitu Zuhair dan kawan-kawan mengenai efek kecelakaan water ingress pada reaktor HTGR sesuai pustaka $^{[20]}$. Selain dari pada itu, telah dilakukan perhitungan inventori reaktor HTR-10 oleh Yuanzhong [ [21] dan Jeong $H^{[22]}$. Yuanzhong $L$ melakukan perhitungan 
menggunakan program ORIGEN2 dengan mengasumsikan teras reaktor terdiri dari 5 buah kanal pendingin (arah radial) serta beberapa titik arah axial. Untuk data pendingin digunakan data kanal ke 3 dimana temperatur pendingin sebesar $587,9{ }^{\circ} \mathrm{C}$. Temperatur ini digunakan sebagai temperatur untuk mengge-nerasi tampang lintang material yang selanjutnya digunakan sebagai data pustaka untuk ORIGEN2. Sedangkan Jeong $\mathrm{H}$ melakukan perhitungan dengan cara menentukan teras setimbang menggunakan program kopling dari program MCNP-MONTEBURNS-ORIGEN yang disebut perhitungan fraksi bakar Monte Carlo (Monte Carlo Burnup Calculation), dimana perhi-tungan pertama kali dilakukan menggu-nakan program MCNP untuk mendapatkan fluks neutron dan tampang lintang material, dan kedua hasil tersebut diambil dan diumpan ke program ORIGEN2. Oleh ORIGEN2 dilakukan perhitungan fraksi bakar material sebagai fungsi waktu dan hasil tersebut diambil oleh MONTEBURNS untuk diumpankan ke MCNP dan diperuntukkan guna memperbarui data material yang digunakan dan hasil akhir yang didapat adalah inventori dari reaktor.

Pada makalah ini disajikan analisis inventori reaktor RDE berdaya $10 \mathrm{MWt}$ hingga $30 \mathrm{MWt}$ dengan tipe reaktor HTGR berbahan bakar Pebble Bed. Analisis yang pertama adalah melakukan perhitungan inventori reaktor RDE $10 \mathrm{MWt}$ berdasarkan reaktor HTR-10 yang memiliki daya similar sebesar $10 \mathrm{MWt}$. Perhitungan inventori di teras reaktor dilakukan dengan menggunakan program ORIGEN2. Dipilih program ORIGEN2, karena program tersebut dapat mensimulasikan deplesi radionuklida hasil dari reaksi fissi pada bahan bakar reaktor. Untuk penggunaan program ORIGEN2 pada reaktor temperature tinggi terlebih dahulu dilakukan generasi tampang lintang untuk pustaka tampang lintang pada kondisi temperature tinggi. Asumsi temperatur yang digunakan adalah temperatur rata-rata reaktor yaitu $475{ }^{\circ} \mathrm{C}$ dikalikan dengan Fraksi
Puncak Daya sebesar 1,20 yaitu sebesar $570{ }^{\circ} \mathrm{C}$. Harga Faktor Puncak Daya sebesar 1,20 berdasarkan perhitungan benchmark HTR-10 merujuk pada pustaka[23]. Pada perhitungan inventori teras RDE $10 \mathrm{MWt}$ teras dibagi dalam arah axial berdasarkan fraksi bakar dengan perbedaan tingkat fraksi bakar sebesar 10.000 MWD/MTH, dengan bahan bakar baru berada di bagian paling atas teras dan fraksi bakar terendah berada di bagian terbawah teras. Iradiasi bahan bakar untuk mencapai fraksi bakar tertentu dilakukan untuk seluruh bahan bakar di teras reaktor dengan daya sebesar $10 \mathrm{MWt}$. Bahan bakar yang berada di teras reaktor berjumlah 27.000 bahan bakar Pebble bed, dengan pengkayaan uranium 17\%, Fraksi bakar maksimum $80.000 \mathrm{MWD} / \mathrm{MTH}$ dan setiap pebble terdiri dari $5 \mathrm{gUO}_{2}$. Setelah diperoleh inventori radionu-klida di teras reaktor kemudian dilakukan perhitungan untuk menentukan fraksi lepasan radionuklida dari teras reaktor ke pendingin dengsn menggunakan program komputer PANAMA ${ }^{[24]}$. Program komputer PANAMA memodelkan bahan bakar TRISO dengan lapisan SiC. Model yang disimu-lasikan adalah ternyadinya tekanan gas internal karena terbentuknya gas Oksigen pada lapisan SiC yang menyebabkan penurunan kekuatan lapisan SiC sebagai akibat dari proses iradiasi pada bahan bakar tersebut. Akibat penurunan kekuatan pada lapisan bahan bakar TRISO suatu saat akan mengakibatkan terdiffusinya radionuklida menerobos lapisan SiC keluar ke sistem pendingin. Berdasarkan rangkaian perhitungan tersebut dilakukan perhitungan untuk menentukan inventori radionuklida di reaktor RDE berdaya $20 \mathrm{MWt}$ dan $30 \mathrm{MWt}$. Langkah yang dilakukan similar dengan langkah pada perhitungan reakotor RDE $10 \mathrm{MWt}$.

Perhitungan inventori radionuklida dilakukan menggunakan program deplesi radionuklida berdasarkan rumusan sebagai berikut ${ }^{[25]}$ : 


$$
\begin{aligned}
& \frac{d X_{i}}{d t}=\sum_{i=1}^{N} I_{i j} \lambda_{i} X_{i}+\phi \sum_{i=1}^{N} f_{i k} \sigma_{k} X_{k}- \\
& \left(\lambda_{i}+\phi \sigma_{i}+r_{i}\right)+F_{i} \ldots \ldots i=1 \ldots V .
\end{aligned}
$$

dengan;

$\mathrm{X}_{\mathrm{i}}=$ densitas atom untuk nuklida $i$

$\mathrm{N}=$ jumlah radionuklida

$\lambda_{\mathrm{i}} \quad=$ konstanta peluruhan radionuklida

lij =.fraksi disintegrasi radionuklida untuk nuklida lain dimulai dari unsur $i$

$\phi \quad=$ fluks neutron

$f_{i k}=$ fraksi absorbsi neutron oleh nuklida lain, dimulai dari unsur $i$

$\sigma_{k} \quad$ = tampang lintang absorbsi neutron dari nuklida $\mathrm{k}$

$\mathrm{r}_{\mathrm{i}} \quad=$ laju kehilangan nuklida i dari sistem

$\mathrm{F}_{\mathrm{i}} \quad$ = laju pembentukan nuklida $i$

sedangkan fluence neutron dihitung dengan rumusan sebagai berikut;

Fluence $=\phi . t$.

Dengan:

$\Phi=$ fluks neutron $\left(\mathrm{n} / \mathrm{cm}^{2}\right.$. detik)

$\mathrm{t} \quad=$ waktu (jam)

dan fluks neutron dihitung berdasarkan persamaan (3) sebagai berikut;

$\phi=\frac{6,242 \times 10^{18}(p)}{\sum_{i} x_{i}^{f} \sigma_{i}^{f} R_{\hat{i}}}$

$R_{i}=1,29927 \times 10^{-3}\left(Z^{2} A^{0,5}\right)+33,12$

Dengan:

$\phi \quad=$ fluks neutron, $\left(\mathrm{n} / \mathrm{cm}^{2} . \mathrm{s}\right)$

$\mathrm{P}=$ daya reaktor, $(\mathrm{Mw})$

$X_{i}^{f}=$ jumlah nuklida hasil fisi i dalam bahan bakar, (gr atom)

$\sigma_{i}^{f}=$ tampang lintang mikroskopik fisi untuk nuklida $\mathrm{i}\left(\mathrm{cm}^{-1}\right)$

$R_{\bar{i}}=$ energi yang dibangkitkan kembali

perfisi untuk nuklida ke i, (MeV/fisi)

$\mathrm{Z}$ = nomor atom

$\mathrm{A}=$ nomor massa

selanjutnya untuk menentukan daya untuk iradiasi bahan bakar untuk program ORIGEN2 memakai rumusan seperti tertera pada persamaan (5); diganti

$P_{\text {irr }}\left(\frac{M W}{M T H}\right)=$

Daya reaktor (MW)

Jumlah bahan bakar pebblesmassa Uranium perpebble(gram) $10^{6}\left(\frac{g r a m}{M T H}\right)$
Sedangkan wanktu iradiasi dalam hari (D/days) dihitung berdasarkan persamaan (6):

$$
\begin{aligned}
& T_{\text {irr }}(D)= \\
& \frac{\text { 80.000 }(\text { MWD } / M T H)}{P_{\text {irrr }}(\text { MW/NTH })}
\end{aligned}
$$

Untuk Fraksi Volume teras menggunakan rumusan sesuai persamaan (7);

$\mathrm{Fvol}_{\mathrm{BB}}=$ Volume Bahan Bakar $/$ Volume

Perhitungan untuk mendapatkan fraksi lepasan dari bahan bakar ke sistem pendingin dilakukan setelah inventori bahan bakar di teras reaktor diperoleh. Perhitungan dilakukan menggunakan program PANAMA. Program PANAMA mengasumsikan fraksi lepasan bahan bakar terjadi karena tiga hal yaitu adanya kegagalan dalam fabrikasi bahan bakar $\left(\phi_{0}\right)$, karena proses irradiasi menghasilkan tekanan gas karena terbentuknya Oksigen didalam lapisan SiC (Pressure Vessel Model $\left.\left(\phi_{1}\right)\right)$ dan karena proses dekomposisi $\left(\phi_{2}\right)$.

$\emptyset_{\text {total }}=1-\left(1-\emptyset_{0}\right) \cdot\left(1-\emptyset_{1}\right)\left(1-\emptyset_{2}\right)$.

Pada kondisi operasi dianggap bahan bakar semua baik, sehingga fraksi lepasan yang berasal dari kegagalan fabrikasi tidak ada yaitu $\phi_{0}=0$ dan pada kondisi operasi normal juga tidak memperhitungkan terjadinya proses dekomposisi yaitu $\phi_{2}=0$. Dengan demikian yang dihitung adalah adanya tekanan pada lapisan SiC dan dimodelkan menggunakan persamaan (10) sebagai berikut:

$\phi_{1}(t, T)=1-e^{\ln 2 \cdot\left(\sigma_{1}-\sigma_{0}\right)^{m}}$

Dengan:

$\mathrm{t} \quad=$ waktu iradiasi

$\mathrm{T}=$ temperatur saat iradiasi

$\sigma_{0}=$ tensil strength dari $S_{i} C$ di akhir

iradiasi $(\mathrm{Pa})$

$\sigma_{1}=$ stress yang terjadi di lapisan SiC karena terbentuknya gas Oxigen

$(\mathrm{Pa})$

dan :

$\sigma_{1}=\frac{r_{s} P}{2 \cdot d_{0}} \cdot\left(1+\frac{V_{s} t}{d_{0}}\right)$ 


\section{Dengan:}

$r=$ rata-rata radius dari lapisa $\mathrm{SiC}(\mathrm{m})$

$\mathrm{p}=$ tekanan gas fisi pada partikel $(\mathrm{Pa})$

$\mathrm{d}_{0}=$ radius awal dari lapisan $\mathrm{SiC}_{\mathrm{i}}(\mathrm{m})$

$\mathrm{v} \quad=$ laju korosi fungsi temperatur $\mathrm{T}(\mathrm{m} / \mathrm{s})$

$\mathrm{t} \quad=$ waktu iradiasi (s)

sedangkan $\sigma_{0}$ adalah:

$\sigma_{0}=\sigma_{00} \cdot\left(1-\frac{\Gamma}{\Gamma_{g}}\right)$

Dengan:

$$
\begin{aligned}
\Gamma & =\text { fluence neutron cepat }\left(10^{25} \mathrm{~m}^{-2}\right) \\
\Gamma_{\mathrm{s}} \quad= & \text { keterkaitan dengan temperatur } \\
& \text { iradiasi }(\mathrm{s})
\end{aligned}
$$

\section{METODOLOGI}

Metoda yang digunakan dalam penelitian ini adalah metode simulasi perhitungan menggunakan program komputer ORIGEN2. Langkah awal adalah menentukan inventori reaktor RDE berdaya $10 \mathrm{MWt}$. Sebagai pustaka adalah reaktor HTR-10 yang memiliki daya sama dengan RDE $10 \mathrm{MWt}$. Adapun spesifikasi dari HTR10 yang digunakan sebagai pustaka dapat dilihat pada Tabel 1.

Tabel 1. Parameter disain dari HTR-10

\begin{tabular}{|c|l|r|}
\hline No. & \multicolumn{1}{|c|}{ Parameter } & Harga \\
\hline 1 & Daya termal reaktor (MW) & 10 \\
\hline 2 & $\begin{array}{l}\text { Tekanan pendingin Helium } \\
\text { (MPa) }\end{array}$ & 3.0 \\
\hline 3 & Diameter teras (cm) & 180 \\
\hline 4 & Tinggi teras (cm) & 197 \\
\hline 5 & Tipe bahan bakar & $\mathrm{UO}_{2}$ \\
\hline 6 & Jenis bahan bakar & Pebble \\
\hline 7 & $\begin{array}{l}\text { Jumlah heavy metal tiap } \\
\text { Pebble (gram) }\end{array}$ & 5 \\
\hline 8 & \begin{tabular}{l} 
Jumlah TRISO setiap pebble \\
\hline 9
\end{tabular} & $\begin{array}{l}\text { Pengkayaan pada bahan } \\
\text { bakar segar (\%) }\end{array}$ \\
\hline 10 & $\begin{array}{l}\text { Jumlah pebble kondisi teras } \\
\text { equilibrium }\end{array}$ & 27000 \\
\hline
\end{tabular}

Asumsi yang diambil pada penelitian ini adalah teras reaktor dalam kondisi equilibrium terdiri dari lapisan bahan bakar dimana setiap lapisan bahan bakar berisi bahan bakar dengan burnup sebesar 10.000 MWD/THM. Lapisan bahan bakar di teras merupakan bahan bakar dengan komposisi lapisan teratas berupa bahan bakar segar dan lapisan terbawah merupakan bahan bakar dengan fraksi bakar (burnup) terbesar yaitu sebesar 70.000 MWD/THM. Bahan bakar yang diiradiasi sebanyak sebanyak $135.000 \mathrm{~g}$ dengan daya $10 \mathrm{MWt}$ hingga mencapai fraksi bakar maksimum sebesar 80.000 MWD/MTH.

Berdasarkan dari data tersebut diatas kemudian dilakukan perhitungan untuk menentukan inventori di teras reaktor menggunakan program ORIGEN2. Input yang diperlukan untuk program ORIGEN2 antara lain berupa massa ${ }^{235} \mathrm{U}$ yang dihitung menggunakan persamaan (8). Sebelum program dijalankan, disiapkan terlebih dahulu data pustaka tampang lintang untuk ORIGEN2 dengan temperatur sesuai dengan temperatur pendingin. Temperatur yang digunakan sebagai temperatur pustaka tampang lintang adalah temperatur rata-rata input $\left(250^{\circ} \mathrm{C}\right)$ dan output $\left(700^{\circ} \mathrm{C}\right)$ dari sistim pendingin primer dikalikan dengan faktor daya teras sebesar 1,20 dan diperoleh harga sebesar $570{ }^{\circ} \mathrm{C}$. Setelah input lengkap dilakukan perhitungan untuk mendapatkan aktivitas inventori dari reaktor RDE $10 \mathrm{MWt}$. Hasil yang diperoleh dibandingkan dengan hasil dari penelitian terdahulu[18]. Penelitian dilanjutkan untuk mendapatkan inventori untuk reaktor RDE $20 \mathrm{MWt}$ dan $30 \mathrm{MWt}$.

Untuk mendapatkan inventori teras reaktor RDE $20 \mathrm{MWt}$ dan $30 \mathrm{MWt}$ dilakukan terlebih dahulu perhitungan untuk memperoleh jumlah bahan bakar yang digunakan di teras reaktor. Asumsi yang diambil adalah perbandingan perbandingan volume bahan bakar dan volume teras sebesar 0,61 untuk daya $20 \mathrm{MWt}$ dan daya $30 \mathrm{MWT}$. Juga ditetapkan kerapatan daya untuk reaktor RDE $20 \mathrm{MWt}$ dan $30 \mathrm{MWt}$ masing-masing sebesar 2,15 dan 2,35. Setelah komposisi bahan bakar di teras reaktor diperoleh, dilakukan perhitungan inventori reaktor dengan cara yang sama dengan menentuka inventori untuk reaktor berdaya $10 \mathrm{MWt}$. 
Perhitungan menentukan lepasan radionuklida dari bahan bakar ke sistem pendingin dilakukan menggunakan program PANAMA. Sebagai masukan adalah sejarah iradiasi bahan bakar, tipe bahan bakar kernel, radius setiap lapisan bahan bakar pebble, serta fluence neutron cepat dengan energy lebih besar dari $0,10 \mathrm{MeV}$ dalam orde $10^{25} \mathrm{n} / \mathrm{m}^{2}$. Fluence neutron diperoleh dari keluaran program ORIGEN2. Hasil yang diperoleh adalah fraksi radionuklida yang lepas dari bahan bakar ke sistem pendingin.
Fraksi bahan bakar selanjutnya digunakan sebagai fraksi sehingga diperoleh inventori bahan bakar yang ada di sistem pendingin reaktor.

\section{HASIL DAN PEMBAHASAN}

Perhitungan inventori reaktor untuk daya $10 \mathrm{MWt}$ dilakukan menggunakan program ORIGEN2. Hasil yang diperoleh adalah jumlah aktivitas radionuklida dalam satuan $\mathrm{Bq}$ dan dapat dilihat pada Tabel 2 dan Gambar 1.

Tabel 2. Perbandingan hasil perhitungan inventori radionuklida dari reaktor RDE $10 \mathrm{MWt}(\mathrm{HTR}-10)$

\begin{tabular}{|c|c|c|c|c|c|}
\hline \multirow{2}{*}{ Radionuklida } & Kuntjoro & Yuanzhong $\mathrm{L}$ & \multirow{2}{*}{ Radionuklida } & Kuntjoro & Yuanzhong L \\
\cline { 2 - 3 } \cline { 5 - 6 } & $\mathrm{dkk}$ & $\mathrm{dkk}$ & & $\mathrm{dkk}$ & $\mathrm{dkk}$ \\
\hline $\mathrm{H}-3$ & $6.27 \mathrm{E}+12$ & $3.81 \mathrm{E}+12$ & Xe-131m & $1.49 \mathrm{E}+14$ & $1.07 \mathrm{E}+14$ \\
\hline $\mathrm{Kr}-83 \mathrm{~m}$ & $1.77 \mathrm{E}+15$ & $1.41 \mathrm{E}+15$ & Xe-133 & $3.00 \mathrm{E}+16$ & $2.05 \mathrm{E}+16$ \\
\hline $\mathrm{Kr}-85$ & $1.04 \mathrm{E}+14$ & $8.75 \mathrm{E}+13$ & Xe-133m & $9.35 \mathrm{E}+14$ & $5.90 \mathrm{E}+14$ \\
\hline $\mathrm{Kr}-85 \mathrm{~m}$ & $3.85 \mathrm{E}+15$ & $3.59 \mathrm{E}+15$ & Xe-135 & $1.46 \mathrm{E}+16$ & $7.94 \mathrm{E}+15$ \\
\hline $\mathrm{Kr}-87$ & $7.39 \mathrm{E}+15$ & $7.12 \mathrm{E}+15$ & Xe-135m & $5.94 \mathrm{E}+15$ & $2.64 \mathrm{E}+15$ \\
\hline $\mathrm{Kr}-88$ & $1.04 \mathrm{E}+16$ & $1.03 \mathrm{E}+16$ & Cs-134 & $1.51 \mathrm{E}+15$ & $3.11 \mathrm{E}+14$ \\
\hline $\mathrm{I}-131$ & $1.45 \mathrm{E}+16$ & $9.77 \mathrm{E}+15$ & Cs-137 & $1.20 \mathrm{E}+15$ & $6.92 \mathrm{E}+14$ \\
\hline $\mathrm{I}-132$ & $1.93 \mathrm{E}+16$ & $1.46 \mathrm{E}+16$ & Rb-88 & $1.06 \mathrm{E}+16$ & $1.03 \mathrm{E}+16$ \\
\hline $\mathrm{I}-133$ & $2.99 \mathrm{E}+16$ & $2.11 \mathrm{E}+16$ & Sr-89 & $1.33 \mathrm{E}+16$ & $1.30 \mathrm{E}+16$ \\
\hline $\mathrm{I}-134$ & $3.02 \mathrm{E}+16$ & $2.47 \mathrm{E}+16$ & Sr-90 & $8.06 \mathrm{E}+14$ & $5.34 \mathrm{E}+14$ \\
\hline $\mathrm{I}-135$ & $2.80 \mathrm{E}+16$ & $1.70 \mathrm{E}+16$ & Ag-110 & $4.20 \mathrm{E}+12$ & $2.16 \mathrm{E}+12$ \\
\hline
\end{tabular}

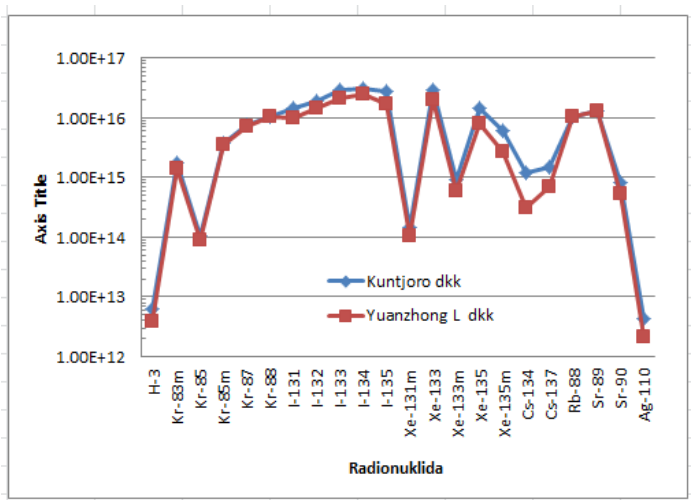

Gambar 1. Perbandingan hasil perhitungan inventori radionuklida dari reaktor RDE 10 MWt (HTR-10)

Dari Tabel 1 dan Gambar 1 terlihat aktivitas tertinggi untuk kelompok krypton berasal dari nuklida $\mathrm{Kr}-88$ sebesar 1.04E16 Bq, untuk kelompok xenon adalah nuklida Xe-133 sebesar 3.00E17 Bq, untuk kelompok iodine adalah nuklida I-134 sebesar 3.02E16 Bq dan untuk kelompok stronsium adalah nuklida $\mathrm{Sr}-89$ sebesar 1.33E16 Bq, dan untuk kelompok Cesium adalah nuklida Cs-134 sebesar $1.51 \mathrm{E} 15 \mathrm{~Bq}$. Dari perbandingan hasil yang diperoleh dibandingkan dengan hasil yang diperoleh dari peneliti terdahulu terdapat kesamaan kecenderungan untuk inventori reaktor. Terdapat kesamaan hasil dengn penelitian yang dilakukan oleh Yuanzhong $\mathrm{L}^{[18]}$.

Selain inventori radionuklida untuk teras RDE $10 \mathrm{MWt}$, juga diperoleh aktivitas radionuklida sebagai fungsi burnup, hasil tersebut dapat dilihat pada Gambar 2, Gambar 3 dan Gambar 4. 


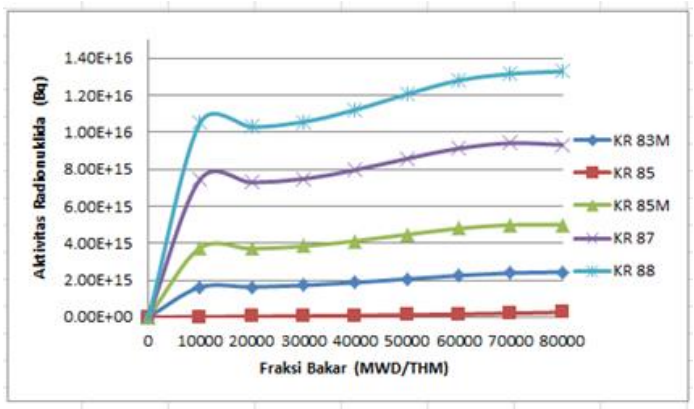

Gambar 2. Aktivitas kelompok radionuklida $\mathrm{Kr}(\mathrm{Bq})$ fungsi fraksi bakar (GWD/MTH)

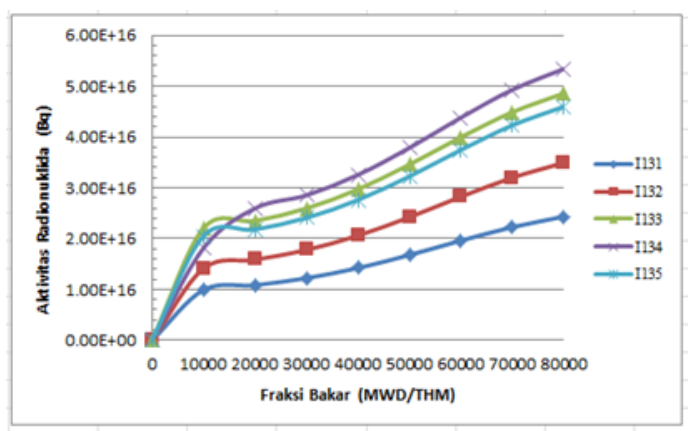

Gambar 3. Aktivitas kelompok radionuklida iodine ( $\mathrm{Bq}$ ) fungsi fraksi bakar (GWD/MTH)

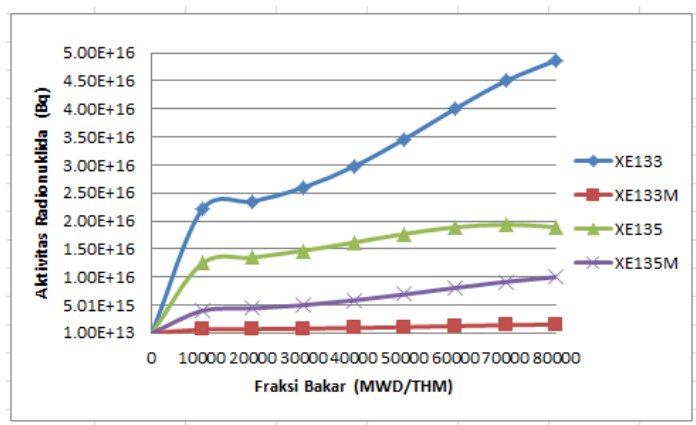

Gambar 4. Aktivitas kelompok radionuklida xenon $(\mathrm{Bq})$ fungsi fraksi bakar (GWD/MTH)

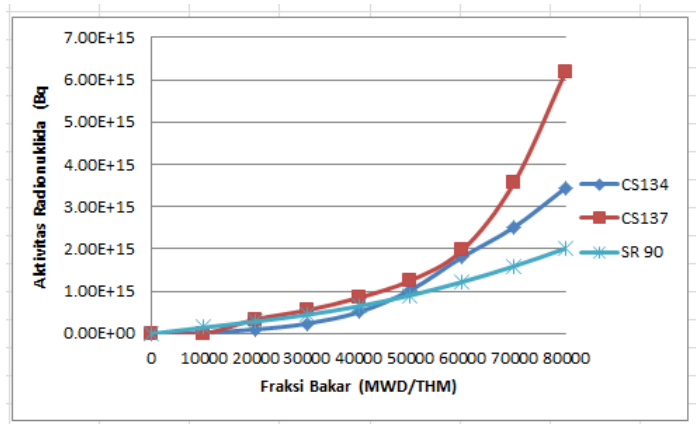

Gambar 5. Aktivitas kelompok radionuklida cesium ( $\mathrm{Bq}$ ) fungsi fraksi bakar WD/MTH)
Gambar 2, 3, 4 dan Gambar 5 terlihat aktivitas nuklida untuk setiap kelompok radionuklida akan bertambah nilainya sebagai fungsi dari fraksi bakar. Hal ini karena noklida-nuklida tersebut merupakan hasil fissi dari uranium, oleh karenanya selama terjadi reaksi fisi nuklida -nuklida tersebut akan terbentuk dan bertambah jumlahnya dengan bertambahnya waktu. Dari gambar-gambar tersebut terlihat terdapat nuklida yang memiliki aktivitas terbesar yaitu Kr-88 untuk kelompok kromium, I-134 untuk kelompok iodine, Xe-133 untuk kelompok xenon dan Cs-137 untuk kelompok cesium. Keempat nuklida tersebut memiliki nilai tertinggi karena memiliki aktivitas setiap MWt terbesar pada kelompoknya yaitu untuk Kr88 sebesar 20,50 Kci/ MWt, Xe-133 sebesar 55,8 KCi/ MWt, l-134 sebesar 55,6 KCi/ MWt serta Cs-137 sebesar 1,16 Kci/ MWt.

Hasil perhitungan tersebut terdapat kesesuaian dengan penelitian yang dihasilkan oleh peneliti terdahulu, dengan demikian dapat disimpulkan metode yang digunakan sudah benar. Berdasarkan hasil tersebut maka metode perhitungan yang digunakan juga dapat digunakan untuk menentukan inventori radionuklida untuk reaktor $20 \mathrm{MWt}$ dan $30 \mathrm{MWt}$. Perhitungan selanjutnya adalah untuk mendapatkan inventori untuk reaktor RDE $20 \mathrm{MWt}$ dan $30 \mathrm{MWt}$ Langkah pertama adalah mendisain parameter reaktor $20 \mathrm{MWt}$ dan $30 \mathrm{MWt}$ berdasarkan data disain parameter reaktor RDE $10 \mathrm{MWt}$. Parameter utama yang dihitung adalah jumlah bahan bakar pebble untuk reaktor berdaya $20 \mathrm{MWt}$ dan 30MW berdasarkan persamaan (7) dan persamaan (8), yaitu dengan mengasumsikan rapat daya untuk Reaktor berdaya $20 \mathrm{MWt}$ dan $30 \mathrm{MWt}$ sebesar 2,15 dan 2,35 dan Fraksi volume bahan bakar sebesar 0,61. Parameter yang diperoleh untuk reaktor RDE $20 \mathrm{MWt}$ dan RDE $30 \mathrm{MWt}$ dibandingkan dengan reaktor RDE 10 MWt dapat dilihat pada Tabel 3. 
Tabel 3. Perbandingan disain parameter reaktor RDE $10 \mathrm{MWt}, 20 \mathrm{MWt}$ dan $30 \mathrm{MWt}$

\begin{tabular}{|l|r|r|r|}
\hline Power (W) & 10000000 & 20000000 & 30000000 \\
\hline $\mathrm{H} / \mathrm{D}$ & 1.10 & 1.10 & 1.10 \\
\hline $\mathrm{D}(\mathrm{cm})$ & 180 & 220 & 246 \\
\hline $\mathrm{H}(\mathrm{cm})$ & 198 & 242 & 270 \\
\hline Volume $(\mathrm{cm} 3)$ & 5003410 & 9265574 & 12786492 \\
\hline PD & 2.00 & 2.15 & 2.35 \\
\hline Fvol & 0.61 & 0.61 & 0.61 \\
\hline Vol . Pabble (cm3) & 3052080 & 5652000 & 7799760 \\
\hline Vol 1 Pabble (cm3) & 113.04 & 113.04 & 113.04 \\
\hline Jumlah Pebble & 27000 & 50000 & 69000 \\
\hline Power Irradiasi (MW) & 10 & 20 & 30 \\
\hline Panjang Siklus (hari) & 1080 & 1000 & 920 \\
\hline Fraksi Bakar (MWD/THM) & 80000 & 80000 & 80000 \\
\hline
\end{tabular}

Berdasarkan Tabel 3 dapat dilihat, jumlah bahan bakar dan daya reaktor untuk mengiradiasi bahan bakar pada perhitungan inventori menggunakan program ORIGEN2 untuk daya $10 \mathrm{MWt}$ dan $20 \mathrm{MWt}$ berturutan adalah 50.000 pebble dan 69.000 pebble serta daya untuk iradiasi bahan bakar sebesar $20 \mathrm{MWt}$ dan $30 \mathrm{MWt}$. Selanjutnya dilakukan perhitungan untuk menentukan inventori reaktor dengan langkah seperti pada perhitungan inventori untuk reaktor $10 \mathrm{MWt}$. Inventori reaktor yang diperoleh dibandingkan dengan inventori reaktor $10 \mathrm{MWt}$ dapat dilihat pada Gambar 5.

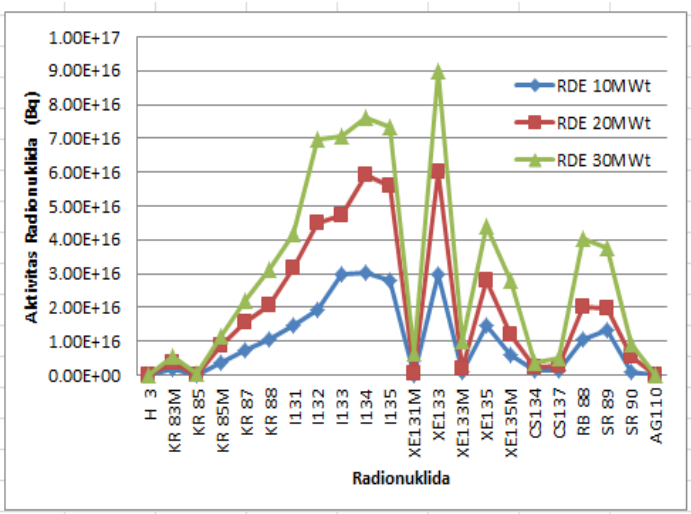

Gambar 5. Perbandingan aktivitas radionuklida inventori reaktor RDE $10 \mathrm{MWt}, 20 \mathrm{MWt}$ dan $30 \mathrm{MWt}$

Berdasarkan Gambar 5 terlihat bahwa aktivitas radionuklida di teras paling besar terdapat pada teras reaktor $30 \mathrm{MWt}$ dan mengecil dengan berkurangnya daya reaktor. Terdapat kecenderungan aktivitas radionuklida yang sama untuk ketiga reaktor. Aktivitas radionuklida bertambah sesuai dengan penambahan jumlah bahan bakar di teras reaktor. Aktivitas radionuklida tertinggi berorde $10^{17} \mathrm{~Bq}$, harga ini cukup kecil karena akan memberikan nilai dosis untuk lingkungan yang kecil.

Setelah inventori radionuklida di teras reaktor diperoleh kemudian dilakukan perhitungan untuk mendapatkan fraksi lepasan dari bahan bakar ke sistem pendingin menggunakan program PANAMA. Sebagai masukan utama adalah Fluence neutron cepat yang digunakan untuk menghitung fraksi lepasan radionuklida. Fluence neutron diperoleh dari perhitungan neutronik untuk energy neutron cepat sebesar 3,50 MeV. Fluence neutron cepat untuk daya reaktor $10 \mathrm{MWt}, 20 \mathrm{MWt}$ dan $30 \mathrm{MWt}$ dapat dilihat pada Tabel 4.

Tabel 4. Fluence neutron cepat energi 3,50 Mev untuk RDE berdaya $10 \mathrm{MWt}$, $20 \mathrm{MWt}$ dan $30 \mathrm{MWt}$

\begin{tabular}{|l|r|r|r|}
\hline \multirow{2}{*}{ Kelompok Radionuklida } & \multicolumn{3}{|c|}{ Fluence Neutron (n/m $\left.\mathbf{m}^{2}\right)$} \\
\cline { 2 - 4 } & RDE 10MWt & RDE 20MWt & RDE 30MWt \\
\hline Kelompok Kr & $1.38 \mathrm{E}+23$ & $8.19 \mathrm{E}+23$ & $6.18 \mathrm{E}+24$ \\
\hline Kelompok I & $4.07 \mathrm{E}+23$ & $1.51 \mathrm{E}+24$ & $1.78 \mathrm{E}+25$ \\
\hline Kelompok CS & $2.56 \mathrm{E}+23$ & $7.83 \mathrm{E}+23$ & $3.59 \mathrm{E}+24$ \\
\hline
\end{tabular}

Tabel 4 memperlihatkan bahwa fluence neutron cepat bertambah besar sebanding dengan kenaikan daya reaktor. Hal ini disebabkan karena jumlah bahan bakar bertambah besar sesuai dengan bertambahnya daya reaktor, sehingga neutron hasil fissi juga bertambah besar sesuai dengan kenaikan daya reaktor tersebut. Selanjutnya dengan memasukkan fluence neutron cepat sebagai input pada PANAMA code diperoleh hasil fraksi lepasan radionuklida terlihat pada Tabel 5 .

Tabel 5. Fraksi lepasan radionuklida untuk RDE $10 \mathrm{MWt}, 20 \mathrm{MWt}$ dan $30 \mathrm{MWt}$

\begin{tabular}{|l|r|r|r|}
\hline \multirow{2}{*}{ Kelompok Radionuklida } & \multicolumn{3}{|c|}{ Fraksi Lepasan Radionuklida } \\
\cline { 2 - 4 } & RDE 10MWt & RDE 20MWt & RDE 30MWt \\
\hline Kelompok Kr & $1.74 \mathrm{E}-07$ & $4.79 \mathrm{E}-07$ & $8.23 \mathrm{E}-07$ \\
\hline Kelompok I & $4.53 \mathrm{E}-07$ & $4.78 \mathrm{E}-07$ & $6.34 \mathrm{E}-07$ \\
\hline Kelompok CS & $4.59 \mathrm{E}-07$ & $5.14 \mathrm{E}-07$ & $2.59 \mathrm{E}-05$ \\
\hline
\end{tabular}

Tabel 5 memperlihatkan bahwa fraksi lepasan radionuklida dari bahan bakar ke 
sistem pendingin sangat kecil, hal ini disebabkan karena fluence neutron $<10^{25}$ $\mathrm{n} / \mathrm{m}^{2}$, sehingga kebolehjadian keluarnya radionu-klida dari bahan bakar sangat kecil dan untuk setiap radionuklida memiliki kebolehjadian lepas yang sama. Bertambah besar sesuai dengan kenaikkan daya reaktor. Berdasarkan fraksi lepasan radionuklida dari bahan bakar ke sistim pendingin, maka dapat ditentukan aktivitas radionuklida yang terdapat di dalam sistem pendingin dengan cara mengalikan aktivitas inventori radionuklida di teras dengan harga fraksi lepasan sebesar yang tertera pada Tabel 5. Inventori reaktor RDE $10 \mathrm{MWt}$, $20 \mathrm{MWt}$ dan $30 \mathrm{MWt}$ di teras reaktor dan di sistem pendingin dapat dilihat pada Tabel 6 dan Tabel 7.

Tabel 6. Inventori di teras reaktor RDE berdaya $10 \mathrm{MWt}, 20 \mathrm{MWt}$ dan $30 \mathrm{MWt}$

\begin{tabular}{|l|r|r|r|l|r|r|r|}
\hline Nuklida & RDE 10MWt & RDE 20MWt & RDE 30MWt & Nuklida & RDE 10MWt & RDE 20MWt & RDE 30MWt \\
\hline H 3 & $6.27 \mathrm{E}+12$ & $1.17 \mathrm{E}+13$ & $1.62 \mathrm{E}+13$ & XE131M & $1.49 \mathrm{E}+14$ & $3.22 \mathrm{E}+14$ & $6.28 \mathrm{E}+15$ \\
\hline KR 83M & $1.77 \mathrm{E}+15$ & $3.55 \mathrm{E}+15$ & $5.32 \mathrm{E}+15$ & XE133 & $3.00 \mathrm{E}+16$ & $5.99 \mathrm{E}+16$ & $8.98 \mathrm{E}+16$ \\
\hline KR 85 & $1.04 \mathrm{E}+14$ & $1.94 \mathrm{E}+14$ & $2.69 \mathrm{E}+14$ & XE133M & $9.35 \mathrm{E}+14$ & $1.87 \mathrm{E}+15$ & $9.87 \mathrm{E}+15$ \\
\hline KR 85M & $3.85 \mathrm{E}+15$ & $8.54 \mathrm{E}+15$ & $1.15 \mathrm{E}+16$ & XE135 & $1.46 \mathrm{E}+16$ & $2.81 \mathrm{E}+16$ & $4.40 \mathrm{E}+16$ \\
\hline KR 87 & $7.39 \mathrm{E}+15$ & $1.55 \mathrm{E}+16$ & $2.22 \mathrm{E}+16$ & XE135M & $5.94 \mathrm{E}+15$ & $1.19 \mathrm{E}+16$ & $2.78 \mathrm{E}+16$ \\
\hline KR 88 & $1.04 \mathrm{E}+16$ & $2.08 \mathrm{E}+16$ & $3.12 \mathrm{E}+16$ & CS134 & $1.21 \mathrm{E}+15$ & $2.25 \mathrm{E}+15$ & $3.83 \mathrm{E}+15$ \\
\hline $\mathrm{I} 131$ & $1.45 \mathrm{E}+16$ & $3.16 \mathrm{E}+16$ & $4.17 \mathrm{E}+16$ & CS137 & $1.40 \mathrm{E}+15$ & $2.85 \mathrm{E}+15$ & $4.98 \mathrm{E}+15$ \\
\hline $\mathrm{I} 132$ & $1.93 \mathrm{E}+16$ & $4.51 \mathrm{E}+16$ & $6.98 \mathrm{E}+16$ & RB 88 & $1.06 \mathrm{E}+16$ & $2.04 \mathrm{E}+16$ & $4.03 \mathrm{E}+16$ \\
\hline $\mathrm{I} 133$ & $2.99 \mathrm{E}+16$ & $4.73 \mathrm{E}+16$ & $7.07 \mathrm{E}+16$ & SR 89 & $1.33 \mathrm{E}+16$ & $1.97 \mathrm{E}+16$ & $3.78 \mathrm{E}+16$ \\
\hline $\mathrm{I} 134$ & $3.02 \mathrm{E}+16$ & $5.93 \mathrm{E}+16$ & $7.62 \mathrm{E}+16$ & SR 90 & $8.06 \mathrm{E}+14$ & $5.45 \mathrm{E}+15$ & $9.00 \mathrm{E}+15$ \\
\hline $\mathrm{I} 135$ & $2.80 \mathrm{E}+16$ & $5.60 \mathrm{E}+16$ & $7.34 \mathrm{E}+16$ & AG110 & $1.80 \mathrm{E}+12$ & $1.58 \mathrm{E}+13$ & $3.11 \mathrm{E}+13$ \\
\hline
\end{tabular}

Tabel 7. Inventori di sistem pendingin reaktor RDE berdaya $10 \mathrm{MWt}, 20 \mathrm{MWt}$ dan $30 \mathrm{MWt}$

\begin{tabular}{|l|r|r|r|l|r|r|r|}
\hline Nuklida & RDE 10MWt & RDE 20MWt & RDE 30MWt & Nuklida & RDE 10MWt & RDE 20MWt & RDE 30MWt \\
\hline H 3 & $2.88 E+06$ & $6.00 E+06$ & $4.19 E+06$ & XE131M & $6.82 \mathrm{E}+07$ & $1.65 \mathrm{E}+08$ & $1.63 \mathrm{E}+09$ \\
\hline KR 83M & $8.14 \mathrm{E}+08$ & $1.82 \mathrm{E}+09$ & $1.38 \mathrm{E}+09$ & XE133 & $1.38 \mathrm{E}+10$ & $3.08 \mathrm{E}+10$ & $2.33 \mathrm{E}+10$ \\
\hline KR 85 & $4.78 \mathrm{E}+07$ & $9.97 \mathrm{E}+07$ & $6.97 \mathrm{E}+07$ & XE133M & $4.29 \mathrm{E}+08$ & $9.61 \mathrm{E}+08$ & $2.56 \mathrm{E}+09$ \\
\hline KR 85M & $1.76 \mathrm{E}+09$ & $4.39 \mathrm{E}+09$ & $2.99 \mathrm{E}+09$ & XE135 & $6.72 \mathrm{E}+09$ & $1.45 \mathrm{E}+10$ & $1.14 \mathrm{E}+10$ \\
\hline KR 87 & $3.39 \mathrm{E}+09$ & $7.97 \mathrm{E}+09$ & $5.74 \mathrm{E}+09$ & XE135M & $2.72 \mathrm{E}+09$ & $6.10 \mathrm{E}+09$ & $7.20 \mathrm{E}+09$ \\
\hline KR 88 & $4.77 \mathrm{E}+09$ & $1.07 \mathrm{E}+10$ & $8.07 \mathrm{E}+09$ & CS134 & $5.56 \mathrm{E}+08$ & $1.16 \mathrm{E}+09$ & $9.92 \mathrm{E}+08$ \\
\hline $\mathrm{I} 131$ & $6.65 \mathrm{E}+09$ & $1.63 \mathrm{E}+10$ & $1.08 \mathrm{E}+10$ & CS137 & $6.40 \mathrm{E}+08$ & $1.46 \mathrm{E}+09$ & $1.29 \mathrm{E}+09$ \\
\hline $\mathrm{I} 132$ & $8.86 \mathrm{E}+09$ & $2.32 \mathrm{E}+10$ & $1.81 \mathrm{E}+10$ & RB 88 & $4.85 \mathrm{E}+09$ & $1.05 \mathrm{E}+10$ & $1.04 \mathrm{E}+10$ \\
\hline $\mathrm{I} 133$ & $1.37 \mathrm{E}+10$ & $2.43 \mathrm{E}+10$ & $1.83 \mathrm{E}+10$ & SR 89 & $6.12 \mathrm{E}+09$ & $1.01 \mathrm{E}+10$ & $9.79 \mathrm{E}+09$ \\
\hline $\mathrm{I} 134$ & $1.38 \mathrm{E}+10$ & $3.05 \mathrm{E}+10$ & $1.97 \mathrm{E}+10$ & SR 90 & $3.70 \mathrm{E}+08$ & $2.80 \mathrm{E}+09$ & $2.33 \mathrm{E}+09$ \\
\hline $\mathrm{I} 135$ & $1.29 \mathrm{E}+10$ & $2.88 \mathrm{E}+10$ & $1.90 \mathrm{E}+10$ & AG110 & $8.26 \mathrm{E}+05$ & $8.11 \mathrm{E}+06$ & $8.06 \mathrm{E}+06$ \\
\hline
\end{tabular}

\section{SIMPULAN}

Pelapisan Inventori reaktor untuk reaktor $\mathrm{RDE}$ berdaya $10 \mathrm{MWt}$ telah diperoleh. Berdasarkan reaktor RDE $10 \mathrm{MWt}$ telah diperoleh parameter disain untuk reaktor RDE berdaya $20 \mathrm{MWt}$ dan $30 \mathrm{MWt}$. Parameter utama antara lain jumlah bahan bakar yaitu sebanyak 50.000 dan 69.000 bahan bakar Pebble $\mathrm{UO}_{2}$ dengan pengkayaan uranium sebesar $17 \%$, diameter teras sebesar $200 \mathrm{~cm}$ dan $220 \mathrm{~cm}$ serta tinggi masing-masing adalah $231 \mathrm{~cm}$ dan $264 \mathrm{~cm}$. Berdasarkan parameter teras tersebut dapat ditentukan pula inventori reaktor untuk reaktor RDE berdaya $20 \mathrm{MWt}$ dan $30 \mathrm{MWt}$. Selain itu juga diperoleh fraksi lepasan radionuklida dari bahan bakar ke sistim pendingin terbesar untuk daya $10 \mathrm{MWt}$, $20 \mathrm{MWt}$ dan $30 \mathrm{MWt}$ secara berururan sebesar 4.59E-07, 5.14E-07 dan 2,59E-05. Dengan diperolehnya fraksi lepasan 
tersebut, maka dapat diperoleh aktivitas radio-nuklida yang berada di dalam sistem pendingin, dengan cara mengalikan aktivitas inventori di teras reaktor dengan harga 4.59E-07 untuk daya $10 \mathrm{MWt}, 5.14 \mathrm{E}-07$ untuk daya $20 \mathrm{MWt}$ dan 2,59E-05 untuk daya $30 \mathrm{MWt}$. Aktivitas inventori sangat kecil dibandingkan dengan inventori reaktor daya yang telah diteliti[1] dalam orde $10^{18} \mathrm{~Bq}$, dimana untuk aktivitas radionuklida dalam orde tersebut memberikan nilai dosis lebih kecil dari batas dosis diijinkan berada dilingkungan sesuai dengan ketentuan badan pengawas yaitu $5 \mathrm{mSv} /$ tahun.

\section{DAFTAR PUSTAKA}

[1] SEMBIRING T, (2014), Kerangka Pustaka Kerja Dokumen Teknis Keselamatan Reaktor Daya Eksperimental, BATAN.

[2] Udiyani PM. (2011), Karakterisasi Radio-Nuklida Pada Tiap Sub-sistem Keselamatan Reaktor Daya Berbahan Bakar MOX, TRI DASA MEGA, Jurnal Teknologi Reaktor Nuklir; 13(2):116119.

[3] Rahgoshay M., Tilehnoee MH., (2013), Calculating the Inventory of Heavy Metals in The Fuel Assemblies of VVER-1000 During the First Cycle, Elsevier, Annals of Nuclear Energy, 3;58:33-35.

[4] Ahmad S-I., Ahmad N., (2006), BurnupDependent Core Neutronics Analysis and Calculation Of Actinide and Fission Product Inventories in Discharged Fuel of a Material Test Research Reaktor, Elsevier, Progress in Nuclear Energy;48:599-616.

[5] El Bakkari B., at all. (2009), Development of an MCNP-Tally Based Burnup Code and Validation Through PWR Benchmark Exercises, Elsevier, Annals of Nuclear Energy, 2009;36:626-633.

[6] Yamamoto T., Yamamoto M., (2008), Analysis of Rod-by-Rod FP Inventory, (2008), Distributions in BWR $8 \times 8 \mathrm{UO}_{2}$ Assemblies Using Lattice Physics
Method, Journal of Nuclear Science and Technolgy, 45(1): 25-35.

[7] Amar H., Su'ud Z., dan Pasek AD. (2011), Source Term Analysis of LongLife 620 MWt BWR During Loss of Coolant Accident (LOCA), Indonesian Journal of Physics, 2011; 22(1).

[8] Yasin Z., lqbal J., Shahzad MI. (2011), Comparison of Radionuclide's Inventories and Activities with Slightly Enriched Uranium and Plutonium Fuel in CANDU Reaktors, World Journal of Nuclear Science and Technology; 1:3136.

[9] Pavelescu., Octavian A., CANDU (2011), Radiotoxicity Inventories Estima-tion: A Calculated Experiment Cross-Check for Data Verification and Validation, World Journal of Nuclear Science and Technology;1:31-36.

[10] Noh K., Chang. dan Hah J. (2015), Radiation Source Term Analysis for Wolsong Unit 1 Using MCNP/ORIGEN, International Journal of Recent Development in Engineering and Technology ISSN Online; 4(2):23476435

[11] Setiadipura T., Irwanto D., Zuhair, (2015), Preliminary Neutronic Design of High Burnup OTTOCycle Pebble Bed Reactor, Jurnal Atom Indonesia; 41(1): 7-15.

[12] Zuhair, Suwoto, Irianto D. Ing. (2010), Pemodelan Teras Untuk Analisis Perhitungan Konstanta Multiplikasi Reaktor HTR-PROTEUS, Jurnal TRI DASA MEGA; 12(2): 91-102.

[13] Suwoto, Zuhair, (2015), Analisis Sensitivitas Ketebalan Reflektor Grafit Teras RGTT200K Menggunakan perhitungan Monte Carlo, Jurnal Pengembangan Energi Nuklir; 16(2): 73-83.

[14] Zuhair, Suwoto, Irianto D. Ing. (2010), Studi Optimasi Moderasi Neutron Dalam Teras HTR Pebble Bed, Jurnal Pengembangan Energi Nuklir; 12(2): 96-106. 
[15] Liem PH., (2016), Impact of New Evaluated Nuclear Data Libraries on Core Characteristic of Innovative Reactor Design, Elsevier, Progress in Nuclear Energy; 87: 74-88.

[16] Abedi A., (2011), An Exact MCNP Modelling of Pabble Bed Reactor, International Journal of Chemical, Molecular, Nuclear, Materials and Metallurgical Engineering; 5(11): 10341038.

[17] Zuhair, Suwoto, Ilham P., (2013), Investigasi Parameter Bahan Bakar reaktor Pebble Dalam Perhitungan Teras Thorium RGTT200K, Jurnal Sain dan Teknologi Nuklir Indonesia; 14(2):65-48.

[18] Zuhair, Suwoto, Irianto D. Ing., (2011), Analisis Perhitungan Koeffisien Reaktivitas Doppler Partikel TRISO Reaktor Temperatur Tinggi, Jurnal Pengembangan Energi Nuklir; 13(1); 1-8.

[19] Powers JJ., (2010), A Review of TRISO Fuel Performance Models, Elsevier, Journal of Nuclear Materials; 405: 7482.

[20] Zuhair, Suwoto, (2015), Analisis Efek Kecela-kaan Water Ingress Terhadap
Reak-ivitas Doppler Teras RGTT200K, Jurnal TRI DASA MEGA; 17(1): 31-40

[21] Yuanzhong L., Jianzu C., Fission, (2002), Product Release and its environment Impact for Normal Reaktor Operations and for Relevant Accident, Elsevier, Nuclear Engineering and Design; 218:81-90.

[22] Jeong H., Chang SH., (2008), Development of a method of evaluating an inventory of fission products for a pebble bed reaktor, Elsevier, Annals of Nuclear Energy; 35: 2161-2171.

[23] IAEA, (2003), Evaluation of High Temperature Gas Cooled Reactor Performance; IAEA-TECDOC-1382: 271-289.

[24] Verfondern K., Nabielek H., (1990), The Mathematical Basis of the PANAMA-I Code for Modelling Pressure Vessel Failure of TRISO Coated Particles under Accident Condition, KFA Julich.

[25] Croff AG, Origen2, (1983), a Versatile Computer Code For Calculating The Nuclide Compositions And Characteristics of Nuclear Materials, P.O. Box Oak Ridge Tennessee 37830 USA, Oak Ridge National Laboratory Chemical Technology Division. 